Е.Н. Имянитов

\title{
THE BIOLOGY OF TUMOR GROWTH
}

\author{
Е.Н. Имянитов \\ Профессор, доктор медицинских наук, \\ илен-корреспондент РАН, \\ НИИ онкологии им. Н.Н. Петрова Минздрава России, \\ 197758, Россия, Санкт-Петербург, пос. Песочный, Ленинградская ул., 68. \\ Тел.: 8 (812) 439-95-55, \\ E-mail:evgeny@imyanitov.spb.ru.
}

\author{
E.N. Imyanitov \\ Professor, Doctor of Medicine, \\ Corresponding Member of the Russian Academy of Sciences, \\ N.N. Petrov Research Institute of Oncology, \\ 197758, Russia, St. Petersburg, Pesochny, Leningradskaya St., 68. \\ Pbone: 8 (812) 439-95-55, \\ E-mail:evgeny@imyanitov.spb.ru.
}

Опухолевые клетки обладают уникальным набором биологических характеристик, отличающих их от нормы: к ним относятся продукция аутопролиферативных сигналов, резистентность к факторам, сдерживающим деление, утрата способности к апоптозу, неограниченный пролиферативный потенциал, инвазия и метастазирование, геномная нестабильность, продукция ангиогенных субстанций, индукция периопухолевой иммуносупрессии, аэробный гликолиз и т.д. Присутствие этих характеристик обеспечивается мутациями в онкогенах и супрессорных генах. Представляют интерес современные исследования, направленные на анализ внутриопухолевой гетерогенности, изучение механизмов метастазирования, получение новых сведений об особенностях взаимоотношений организма и опухоли и т.д.

ключевые слова: опухолевый процесс, опухолевые клетки, характеристики, опухоль.

Malignant cells own an unique spectrum of biological characteristics, such as production of auto proliferative signals, resistance to growth suppressing factors, loss of apoptotic capacity, unlimited proliferative potential, invasion and metastasis, genomic instability, secretion of angiogenic factors, induction of peritumoral immune suppression, aerobic glycolysis etc. These properties are attributed to mutations in oncogenes and suppressor genes. Recent advances in experimental oncology attract attention to the existence of intratumoral heterogeneity, novel views on the mechanisms of tumor metastasis, investigations of tumor-host interactions etc.

Keywords: tumor growth, malignant cells, properties, tumor. 


\section{Понятия и термины, используемые в молекулярной генетике}

Повседневная работа врача-онколога требует свободного владения терминами, используемыми в молекулярной генетике. Представляется необходимым обсудить несколько понятий, регулярно используемых в онкологической литературе.

Процесс онкогенеза практически всегда начинается с повреждения ДНК. Под повреждением ДНК подразумевается нарушение пространственной структуры этой молекулы - например, появление разрывов, нарушение шага двойной спирали, присоединение различных химических групп к нуклеотидам и т.д. В норме подобные нарушения распознаются специальными ферментами и устраняются системами репарации ДНК. Если повреждение ДНК всё же сохраняется, то запускается программа клеточной гибели и клетка самоустраняется по механизму апоптоза. Например, именно этот механизм реализуется при воздействии цисплатина или олапариба на BRCA1-дефицитные опухоли: перечисленные выше препараты увеличивают количество повреждений ДНК, а отсутствие функции BRCA1, являющегося ферментом репарации ДНК, приводит к гибели клеток [15]. В случае нарушений процессов апоптоза клетки могут продолжать функционировать, невзирая на персистенцию повреждений ДНК - в процессе митоза последние конвертируются в мутации.

Под мутациями подразумевается нарушение последовательности нуклеотидов - если мутации затрагивают кодирующие области генома, то они могут приводить к нарушениям аминокислотной последовательности белков. Не следует путать мутации с упомянутыми выше повреждениями ДНК: в случае мутаций речь идёт не о нарушении химической структуры ДНК, а об изменении сути генетического кода.

Мутации, возникающие при делении «обычных» клеток организма, принято называть соматическими именно они являются причиной трансформации нормальной клетки в опухолевую. Соматические мутации не передаются по наследству. Мутациями также называют редкие, заведомо патогенные варианты генов, которые предрасполагают к возникновению медико-генетических патологий - эти мутации называют наследственными. Следует понимать, что за похожими терминами подразумеваются два достаточно разных процесса. В случае соматической мутации речь идёт об изменении генетического кода, наблюдаемого при делении клетки: обычно диагноз соматической мутации устанавливается посредством сравнения опухолевой и нормальной ДНК.

Под термином «наследственные мутации» подразумевается персистенция в популяции определённых генотипов: в этой ситуации диагноз ставится посредством сравнения ДНК того или иного индивидуума с ДНК «здорового» человека, при этом в само понятие наследственной мутации вкладывается не только сам факт отличия от популяционного стандарта, но и наличие сведений о причастности данного варианта последовательности ДНК к формированию той или иной наследственной патологии. Некоторые наследственные мутации не могут легко передаваться детям от родителей, т.к. они приводят к резкому снижению шансов оставить потомство. В этом контексте представляется целесообразным сравнить эпидемиологию мутаций, ассоциированных с различными наследственными опухолевыми синдромами. Например, присутствие мутаций в генах BRCA1 или BRCA2 проявляется в увеличении риска рака молочной железы и рака яичников и манифестирует примерно в середине жизни - повреждения этих генов характеризуются, как правило, вертикальной передачей из поколения в поколение [3]. Напротив, мутации в гене р53, ассоциированные с синдромом Ли-Фраумени, дают о себе знать уже в детском и подростковом возрастеи проявляются возникновением множественных опухолей соответственно, в реальной жизни эти мутации часто наблюдаются denovo, т.е. присутствуют в генотипе у ребёнка, но отсутствуют у его родителей [6].

Разновидности мутаций также обозначаются специфическими терминами. Например, увеличение копийности генов называется амплификацией: при этом вместо двух родительских копий количество последовательностей одного и того же гена возрастает примерно в 5-50 раз; соответственно, если все амплифицированные копии транскрибируются, то возрастает количество белкового продукта. Подобный тип активации характерен для геновHER2, NMYC, MDM2 и др. [17]. Утрата генетического материала называется делецией. Делеции могут охватывать как большие участки хромосом, содержащие несколько генов, так и короткие последовательности нуклеотидов.

Мутации, затрагивающие небольшие последовательности ДНК, могут приводить к самым различным последствиям. Например, замены нуклеотидов, приводящие к изменению соответствующей аминокислоты, называются миссенс-мутациями. Миссенс-мутации характерны для генов KRAS, p53, BRAF. Т.к. на 20 аминокислот приходится 64 варианта нуклеотидных триплетов, то некоторые аминокислоты могут кодироваться не одним, а несколькими триплетами. Если замена нуклеотида происходит таким образом, что новый кодон кодирует ту же самую аминокислоту, то такая мутация называется молчащей. Три из упомянутых 64 вариантов триплетов кодируют не аминокислоты, а стоп-кодоны. Соответственно, некоторые нуклеотидные замены приводят к преждевременному образованию стоп-кодонов - эти т.н. нонсенс-мутации зачастую сопровождаются полной инактивацией соответствующего белка. К столь же катастрофическим функциональным последствиям приводят т.н. сдвиги рамки считывания - делеции или инсерции (вставки) нескольких нуклеотидов, в 
которых количество оснований не делится на три. В этом случае, начиная с участка делеции или вставки, полностью искажается трёхбуквенное прочтение генетического кода. Микромутации, приводящие к полной инактивации гена, характерны, например, для генов BRCA1 и BRCA2.

Гены могут оставаться молчащими или транскрибировать РНК. Активность гена - производство продукта - называется его экспрессией. Если активность гена измеряется посредством анализа количества соответствующего транскрипта, например, при помощи ПЦР, то речь идёт о его РНК-экспрессии. Для анализа активности генов зачастую применяется иммуногистохимический (ИГХ) метод - в этом случае уровень экспрессии оценивается на уровне белка. Например, в мультигенных тестах, применяемых для анализа уровня агрессивности рака молочной железы (РМЖ), в частности, Oncotype DX, уровень әкспрессии рецепторов эстрогенов, прогестерона и HER2 исследуется на уровне РНК, а в условиях повседневной клинической практики для этой цели применяют ИГХ.

Детекция белка не всегда является достаточным методом для оценки функциональной активности того или иного сигнального каскада. После своего синтеза на матрице РНК - этот процесс происходит на рибосомах и называется трансляцией - белки могут подвергаться пострансляционной модификации. Например, аминокислоты тирозин, серин и треонин могут находиться как в нефосфорилированном, так и в фосфорилированном состояниях. Фосфорилирование этих аминокислот играет важную роль в регуляции активности белков и осуществляется, соответственно, тирозин- и серин-треониновыми киназами.

Ген не является непрерывной нуклеотидной последовательностью в полном смысле этого слова. У большинства живых организмов, за исключением бактерий и вирусов, гены состоят из кодирующих участков (экзонов) и некодирующих последовательностей (интронов). После своего синтеза образовавшиеся РНК-транскрипты способны самостоятельно удалять из своей последовательности некодирующие участки - этот процесс называется сплайсингом. Существенно, что набор кодирующих фрагментов внутри зрелой РНК может варьировать - разумеется, это непосредственно сказывается на композиции соответствующего белка. Этот феномен называется альтернативным сплайсингом. Он играет важную роль в обеспечении разнообразия функций, выполняемых каждым геном. Роль альтернативного сплайсинга можно проиллюстрировать вариантом гена рецептора андрогенов, AR-V7, который обеспечивает резистентность рака простаты к эндокринной терапии [2].

Ещё одним важным биологическим процессом является метилирование регуляторных областей генов. Метилирование, как правило, захватывает про- моторы - участки генов, расположенные непосредственно перед кодирующими последовательностями и являющиеся сайтом для связывания различных факторов транскрипции. Основной мишенью для метилирования выступают цитозины - именно поэтому метилцитозин иногда называют пятым основанием ДНК. Как правило, цитозины метилируются в том случае, если они расположены перед гуанинами - такие последовательности обозначают $\mathrm{CpG}$, где р маркирует фосфатную группу между расположенными на одной цепи и ковалентно связанными C и G. Считается, что метилирование регуляторных цитозинов приводит к угнетению экспрессии соответствующего гена [5]. Анализ метилирования гена применяется для персонализации терапии глиобластом - низкая экспрессия MGMT свидетельствует о целесообразности назначения темозоломида [24].

\section{Универсальные характеристики злокачественных опухолей}

Онкологические патологии представляются самой главной медицинской проблемой современной цивилизации - они занимают лидирующие места в структуре смертности развитых стран мира. Окончательный вердикт в отношении диагноза онкологического заболевания обычно выносится морфологом или цитологом: современная медицинская наука выработала целый ряд визуальных критериев, которые позволяют практически безошибочно отличить нормальную клетку от опухолевой. Тем не менее, несмотря на кажущуюся очевидность морфологических характеристик опухолевых тканей и их отличий от нормы, длительное время учёным не удавалось сформулировать, в чём именно заключается биологическая суть процесса злокачественной трансформации. Например, опухолевым клеткам приписывалась способность быстро делиться. Несмотря на правильность подобного наблюдения, многие специалисты отмечали существование большого количества новообразований, которые не отличались повышенной скоростью пролиферации, но, тем не менее, представляли ничуть не меньшую опасность для жизни, чем карциномы с высоким индексом деления. Другое частое наблюдение заключалось в утрате клетками дифференцированного фенотипа; опять же, эта характеристика не являлась в полной мере универсальной, при этом многие опухоли приобретали новые биохимические свойства, характерные для дифференцированных клеток, например, способность продуцировать определённые биологически активные молекулы. Колоссальная заслуга в формулировании основных свойств злокачественного фенотипа принадлежит двум учёным, Douglas Hanahan и Robert Weinberg, которые сумели обобщить полувековые усилия учёных-онкологов и предложили перечень обязательных характеристик злокачественного процесса [10, 11]. 
Следует помнить, что под опухолью мы всегда понимаем присутствие избыточного количества клетокт.н. «плюс-ткань». В рамках программ медицинского образования несколько запутывают термины, описывающие определённые разновидности новообразований - например, «рак-язва». В последнем случае подразумевается, что в самой опухоли («плюс-ткань») наблюдается изъязвление («минус-ткань»). Примечательно ещё одно универсальное свойство опухолей. В нормальном многоклеточном организме ни одна клетка не может делиться сама по себе - у клеток не существует «встроенной» программы к делению. Удвоение клетки происходит только в том случае, если от регуляторных систем организма поступает сигнал к пролиферации. Опухолевые клетки, в отличие от нормальных, утратили зависимость от регуляторных систем организма - они приобрели способность к т.н. «автономности».

Поддержание опухолевого фенотипа обеспечивается целым рядом биологических процессов, каждый из которых почти всегда присутствует в злокачественном новообразовании.

Практически все опухоли характеризуются активацией молекул, запускающих клеточное деление. В норме подобные стимулы (гормоны, факторы роста и т.д.) поступают к клетке извне. Трансформированные клетки, в отличие от нормальных, приобретают способность сами продуцировать стимуляторы своего же деления. Способность к аутостимуляции может быть связана с продукцией лиганда, амплификацией рецептора, отвечающего на сигналы к делению, активирующей мутацией в одном из промежуточных белков пролиферативного сигнального каскада и т.д.

Многоклеточные организмы выработали механизмы, позволяющие им защищаться от избыточных масс клеток. В случае появления клона, характеризующегося аномальной пролиферацией, организм посылает к подобному очагу пролиферации сигналы к остановке деления. В отличие от нормальных, опухолевые клетки утратили способность отвечать на подобные сигналы. Это связано с утратой соответствующих рецепторов, сигнальных белков, транскрипционных факторов и т.д., участвующих в сдерживании пролиферации.

Ещё одним механизмом, препятствующим развитию опухолей, является апоптоз. В условиях многоклеточного организма клетки обычно не гибнут сами по себе - этот процесс запускается специальной программой. Программируемая клеточная гибель регулируется не менее тонко, чем клеточное деление для этого к клетке изнутри или извне поступают специальные сигналы, запускается экспрессия определённых генов, затрачивается энергия и т.д. Апоптоз может инициироваться как в результате возникновения повреждений ДНК, с целью предотвращения появления опасных мутаций, так и в ответ на внешние сигналы, позволяющие способствовать обновлению клеток и препятствовать накоплению избыточной клеточной массы. Опухолевые клетки, в отличие от нормальных, утратили полноценную способность к апоптозу - они могут персистировать даже в случае появления несовместимых с жизнью повреждений генома и не реагируют на внешние сигналы к программируемой гибели $[7,8]$.

Даже столь опасный клон, который стимулирует к делению сам себя, не отвечает на сигналы к прекращению деления и утратил способность к апоптозу, не способен создать видимую опухоль. В норме клетки не могут делиться бесконечно - этот потенциал заканчивается после 60-150 делений. Ограничение репликативного потенциала, получившее название «лимита Хэйфлика», является важнейшим барьером на пути к возникновению опухолей - например, именно в связи с этим феноменом нормальные клетки, в отличие от опухолевых, не могут бесконечно пассироваться в культуре. Трансформированные клетки утратили лимит Хэйфлика - они могут породить бесконечное число потомков и, следовательно, нарастить любую опухолевую массу [21].

Самое клинически заметное отличие опухолевых клеток от нормальных заключается в их способности к проникновению в окружающие ткани и диссеминации по организму - эти свойства обычно описываются как инвазия и метастазирование. Примечательно, что даже эта, чрезвычайно зловещая особенность опухолевых клеток не является уникальной для процесса злокачественной трансформации - сходные процессы характерны для некоторых неопухолевых заболеваний, например, эндометриоза. Именно с инвазией и метастазированием связано подавляющее большинство случаев летального исхода онкологических заболеваний.

Совершенно очевидно, что патогенез рака включает достаточно большое число достаточно разнородных, дискретных биологических событий. Если попытаться оценить скорость естественного появления мутаций в нормальной клетке, то на накопление столь большого числа фенотипических признаков должны уходить многие тысячи лет. На самом деле, риск заболеть раком на протяжении обычной продолжительности жизни составляет примерно 50\% - это связано с тем, что на определённом этапе злокачественной трансформации пренеопластические клетки становятся генетически нестабильными и начинают накапливать мутации с многократно увеличенной скоростью. Примечательно, что именно геномная нестабильность, возникающая вследствие дефектов репарации ДНК, является основной мишенью для воздействия цитостатических препаратов.

Ещё одной универсальной особенностью опухоли является продукция факторов, направляющих формирование сосудистой сети. Это свойство несколько противоречит интуитивной логике, в соответствии с которой прорастание сосудами увеличивающейся 
опухолевой массы является относительно пассивным, самим собой разумеющимся процессом. На самом деле, именно опухолевые клетки начинают секретировать факторы ангиогенеза - в противном случае они попросту не могут сформировать видимые опухолевые очаги, несмотря на присутствие всех перечисленных выше характеристик злокачественного фенотипа. Считается, что ангиогенез является достаточно специфичной мишенью для противоопухолевой терапии - действительно, во взрослом организме формирование новых сосудов наблюдается преимущественно при заживлении ран. Разработка препаратов, предназначенных для подавления ангиогенеза, является популярным направлением поиска новых методов лечения рака [4].

Ещё одно существенное свойство опухолей - наличие локальной иммуносупрессии. Опухолевые клетки могут обеспечивать экспансию трансформированного клона только в том случае, если они продуцируют в окружающую ткань иммуносупрессирующие вещества. Именно этим свойством объясняются многолетние неудачи найти у онкологических пациентов системные нарушения иммунитета; на самом деле, ускользание опухолевых антигенов из-под контроля обеспечивается исключительно локальными процессами. В этом десятилетии приобрели огромную популярность лекарственные препараты, которые могут инактивировать выделяемые опухолью иммуносупрессорные субстанции - они получили название ингибиторов контрольных точек иммунного ответа. Иммуномодулирующая терапия уже активно применяется для лечения меланомы, рака лёгкого, опухолей мочевого пузыря и т.д. [9].

Одной из интересных особенностей опухолей является способность метаболизировать глюкозу по анаэробному пути даже в присутствии нормального количества кислорода. В норме распад глюкозы происходит, преимущественно, по аэробному пути - подобный процесс называется клеточным дыханием. Привлечение к процессу распада молекул кислорода позволяет получать наибольшее количество молекул АТФ (эквивалента энергии) с каждой молекулы глюкозы. Однако, в этом случае на получение АТФ требуется достаточно большое количество времени. При нехватке кислорода (гипоксии) клетки могут разлагать глюкозу в әкстренном порядке - по механизму гликолиза; в этом случае АТФ образуется очень быстро, но в значительно менышем количестве. Великий немецкий биохимик, Отто Варбург, обратил внимание на тот факт, что опухолевые клетки, в отличие от нормальных, вне зависимости от концентрации кислорода склонны разлагать глюкозу по гликолитическому пути - по-видимому, именно гликолиз является предпочтительным для постройки новых органелл, необходимых для удовлетворения потребностей быстро делящихся клеток. Это свойство злокачественных клеток легло в основу позитронно- эмиссионной томографии (ПЭТ) - методе, основанном на накоплении радиоактивно меченой глюкозы опухолевыми тканями [19].

Разумеется, перечисленные выше свойства не являются абсолютной догмой. Более того, данный список постоянно пополняется. Например, многие специалисты предлагают рассматривать в качестве обязательной характеристики рака т.н. эпителиально-мезенхимальный переход (epithelialmesenchymal transition, EMT): под әтим понятием подразумевается появление у эпителиальных опухолевых клеток маркеров соединительно-тканного происхождения, а также приобретение ими способности активно передвигаться по организму. Феномен эпителиальномезенхимального перехода в определённой степени связан с морфологическими характеристиками, которые обычно рассматриваются как дедифференцировка - в этом контексте целесообразно упомянуть наблюдаемую в карциномах утрату эпителиальных антигенов [22].

Обязательное присутствие каждой из перечисленных выше характеристик в каждой опухоли тоже является условным. Например, глиобластомы, которые являются одной из наиболее злокачественных разновидностей новообразований, достаточно редко метастазируют. Карциномы молочной железы и простаты далеко не всегда характеризуются полной автономностью - они могут сохранять зависимость от стероидных гормонов. ПЭТ, несмотря на всю свою привлекательность, не является абсолютно универсальным методом диагностики опухолей - повидимому, далеко не все новообразования действительно ассоциированы с феноменом Варбурга. Тем не менее, структуризация знаний об отличиях опухолевых клеток от нормальных позволяет осмысленно выбирать наиболее перспективные направления поиска новых методов борьбы с раком.

\section{Генетические события, лежащие в основе злокачественной трансформации}

В основе открытия генетических детерминант, лежащих в основе злокачественного перерождения клеток, лежат судьбоносные опыты по экспериментальному канцерогенезу. Длительное время специалисты наблюдали множество альтернативных путей возникновения неоплазм - например, рак молочной железы у мышей можно было вызывать воздействием половых гормонов, введением химических канцерогенов, заражением онкогенными вирусами, облучением и т.д. Более того, были получены линии мышей, характеризующиеся наследственной предрасположенностью к раку. Всё это вносило необычайный хаос в представления о природе злокачественного роста - создавалось ощущение, что у столь сложного и комплексного феномена нет и не может быть единых биологических причин. 
Принципиальный толчок к формированию современных представлений о развитии рака дало развитие методов молекулярной биологии. В начале 1970-х гг. появились технологии, которые позволили «раздробить» геном онкогенных вирусов на отдельные фрагменты. К удивлению учёных оказалось, что за весь процесс злокачественной трансформации у вируса отвечает всего один ген - эти гены стали называть онкогенами. Примерно в это же время учёные разработали метод гибридизации нуклеиновых кислот, позволяющий выявлять присутствие в геноме родственных нуклеотидных последовательностей. Дальнейшие эксперименты показали, что практически все вирусные онкогены имеют гомологов в геноме млекопитающих. Окончательный и безоговорочный триумф молекулярной онкологии датируется началом 1980-х гг. - он связан с появлением методов анализа нуклеотидной последовательности ДНК, в частности, с разработкой технологии секвенирования. Примерно в это время удалось выяснить, что структура онкогенов в опухолях несколько отличается от таковой в нормальных клетках. Помимо этого, было установлено, что в норме онкогены играют важнейшую роль в осуществлении различных клеточных функций. Таким образом, свелись воедино все многочисленные теории канцерогенеза: стало понятно, что воздействие неблагоприятных канцерогенных факторов реализуется через патологическую активацию клеточных онкогенов, которые в условиях здорового организма обеспечивают гомеостаз нормальных тканей. В случае же вирусного канцерогенеза активированный онкоген привносится в клетку вирусом.

В целом, к онкогенам относятся гены, которые 1) в норме обеспечивают прирост числа клеток, 2) активируются в ходе превращения нормальной клетки в опухолевую и 3) способствуют опухолевой трансформации в экспериментах на клеточных культурах и животных. На рубеже 1980-х и 1990-х гг. был открыт новый класс генов, обладающих противоположными функциями - их назвали антионкогенами или супрессорными генами. К супрессорным генам относятся гены, которые 1) в норме сдерживают прирост числа клеток, 2) инактивируются в ходе превращения нормальной клетки в опухолевую и 3) препятствуют опухолевой трансформации в экспериментах на клеточных культурах и животных. Считается, что в процессе превращения нормальной клетки в опухолевую участвуют мутационные события, изменяющие функцию как минимум 4-9 онкогенов и супрессорных генов.

В этом контексте приобретает огромное значение вопрос о значимых («драйверных») и «фоновых» (пассажирских») мутациях, наблюдаемых в опухолевых клетках. Как упоминалось выше, опухолевые клетки характеризуются высокой степенью генетической нестабильности, поэтому в новообразованиях, возникающих у человека, современные методы моле- кулярной генетики позволяют обнаружить десятки и даже сотни различных мутаций. Более того, в отношении многих генетических событий отмечается внутриопухолевая гетерогенность: одни участки опухоли содержат ту или иную мутацию, в то время как другие её области подобной мутации не имеют. Современная наука полагает, что полный «комплект» драйверных мутаций формируется в самом начале процесса злокачественной трансформации, на стадии анатомически невидимых микроочагов опухолевого роста. Соответственно, большинство опухолей демонстрирует относительную гомогенность в отношении значимых мутаций, поражающих онкогены и антионкогены. В то же время, в отношении «фоновых» (относительно второстепенных) мутаций может наблюдаться значительная внутриопухолевая гетерогенность. Тем не менее, эти правила не отрицают возможности эволюции определённых опухолевых очагов, в частности, появления дополнительных значимых мутаций в отдельных метастазах. Более того, на целом ряде моделей открепление метастазирующих клеток происходит ещё до появления видимой первичной опухоли - соответственно, метастазы могут обладать несколько иным набором генетических событий. Наиболее явные изменения генетического портрета новообразований наблюдаются на фоне противоопухолевой терапии: в данном случае происходит практически моментальная селекция клонов, характеризующихся резистентностью к лекарственным воздействиям. Накоплено огромное количество примеров мутаций, ассоциированных с устойчивостью к цитостатическим или таргетным препаратам; подобные мутации могут возникать denovo и/или персистировать в единичных опухолевых клетках. Эти мутации (популяции трансформированных клеток) заполняют основную массу новообразования уже в первые недели лекарственного воздействия $[1,18,25]$.

\section{Новые тенденции в представлениях о биологии опухолевого роста}

Большим достижением экспериментальной онкологии является установление факта клональности опухолей. Действительно, в основе появления практически всех новообразований лежит злокачественная трансформация одной клетки, которая выступает в роли родоначальника опухоли. Эти сведения практически автоматически были трансформированы в представления об относительной однородности (эквивалентности) свойств клеток внутри каждого отдельного новообразования.

На рубеже 1990-х и 2000-х гг. стали появляться технологии, которые позволяют эффективно сортировать различные популяции клеток внутри опухоли. Оказалось, что многие новообразования поддерживают относительное многообразие клеточного состава, в котором существуют отдельные популяции клеток с 
необычными функциями. Например, получили распространение представления о т.н. стволовых клетках опухоли - небольшой популяции трансформированных клеток, которые обладают характерным спектром поверхностных белков, персистируют в опухолевой массе, демонстрируют относительную устойчивость к терапии и обеспечивают репопуляцию опухоли между циклами лечения. Эти клетки способны порождать «обычные» клетки опухоли, идентифицируемые по иному спектру поверхностных белков - таким образом, «стволовые» клетки новообразований демонстрируют определённую способность к дифференцировке [20].

Краеугольным правилом онкологии является представление о целесообразности ранней диагностики рака, вне зависимости от типа новообразования. Это убеждение основывается на классической модели опухолевой трансформации, в соответствии с которой сначала появляется исходная злокачественная клетка, потом формируется первичная опухоль и только после этого запускается процесс метастазирования. Недавние исследования демонстрирует, что этот сценарий патогенеза опухолевого роста не всегда является догмой. Описаны модели, в которых метастатические клетки открепляются от основной опухолевой массы ещё до формирования первичного очага, при этом они заметно отличаются по своим свойствам от массы клеток, составляющих «основную» опухоль. Сведения о раннем начале процесса метастазирования объясняют ограниченную медицинскую эффективность мероприятий по скринингу рака [12, 13].

Ещё одним важным стандартом лечения онкологических пациентов является представление о необходимости радикального избавления от опухолевых клеток. Именно поэтому многие онкологические пациенты подвергаются обширным, зачастую калечащим операциям. Тем не менее, существуют данные, что даже видимо радикальные операции не приводят к полному избавлению от элементов опухоли. Более того, трансформированные клетки могут персисти- ровать десятки лет в организме пациента, как до манифестации онкологического заболевания, так и после излечения от него. Представляется весьма вероятным, что существуют достаточно дискретные условия, которые обеспечивают определённое равновесие между ограниченным пулом опухолевых клеток и вполне здоровым статусом макроорганизма; именно нарушение этих условий приводит к прогрессии опухолевых очагов. Вероятно, изучение сложных механизмов взаимодействий между трансформированными клетками и организмом хозяина позволит обозначить новые пути лечения рака [16].

Практически вся диагностика опухолей сегодня ориентирована на анализ опухолевой массы, удалённой на момент диагноза заболевания. Все дальнейшие медицинские мероприятия проводятся на основе исходных морфологических и молекулярно-генетических характеристик, без учёта динамики биологического статуса опухоли. Существует целый массив данных, свидетельствующих практически о моментальном изменении спектра опухолевых клеток в самом начале системной терапии [23]. Соответственно, назначение новых линий терапевтических воздействий на основе исходных свойств опухоли может оказаться совершенно бесперспективным. В настоящее время стремительно развивается идеология повторных биопсий, в соответствии с которой пациент многократно подвергается дополнительным анализам по ходу лечения. Возможности ребиопсии метастатических очагов представляются несколько ограниченными, в связи с необходимостью повторных инвазивных вмешательств и игнорированием внутриопухолевой гетерогенности в отношении механизмов формирования лекарственной резистентности. В этом плане большие надежды возлагаются на т.н. «жидкостную биопсию», позволяющую мониторировать генетические изменения в опухоли посредством генетического анализа циркулирующих трансформированных клеток или опухолевой ДНК [14].

\section{Список литературы}

1.Amirouchene-Angelozzi N., Swanton C., BardelliA. Tumor Evolution as a Therapeutic Target. Cancer Discov. 2017. (in press).

2. Antonarakis E.S., Lu C., Wang H., Luber B., Nakazawa M., Roeser J.C., Chen Y., Mobammad T.A., Chen Y., Fedor H.L., Lotan T.L., Zheng Q., De Marzo A.M., Isaacs J.T., Isaacs W.B., Nadal R., Paller C.J., Denmeade S.R., Carducci M.A., Eisenberger M.A., LuoJ. AR-V7 and resistance to enzalutamide and abiraterone in prostate cancer. N Engl J Med. - 2014 Sep 11. - Vol. 371, №11, - P. 1028-38.

3. Bogdanova N., Helbig S., Dörk T. Hereditary breast cancer: ever more pieces to the polygenic puzzle. Hered Cancer ClinPract. - 2013 Sep 11. - Vol. 11, №1. - P. 12.

4. Carmeliet P., Jain R.K. Molecular mechanisms and clinical applications of angiogenesis. Nature. - 2011 May 19. - Vol. 473, №7347. - P. 298-307.

5. Chatterjee A., Rodger E.J., Eccles M.R. Epigenetic drivers of tumour igenesis and cancer metastasis. Semin Cancer Biol. - 2017. (in press).

6. Correa H. Li-Fraumeni Syndrome. J Pediatr Genet. - 2016 Jun. - Vol. 5, №2. - P. 84-8. 
7. Croce C.M., Reed J.C. Finally, an Apoptosis-Targeting Therapeutic for Cancer. Cancer Res. - 2016 Oct 15. Vol. 76, №20. - P. 5914-5920.

8. Dillon C.P., Green D.R. Molecular Cell Biology of Apoptosis and Necroptosis in Cancer. Adv Exp Med Biol. 2016. - Vol. 930. - P. 1-23.

9. Granier C., De Guillebon E., Blanc C., Roussel H., Badoual C., Colin E., Saldmann A., Gey A., Oudard S., Tartour E. Mechanisms of action and rationale for the use of checkpoint inhibitors in cancer. ESMO Open. - 2017 Jul 3. Vol. 2, №2. - e000213.

10. Hanaban D., Weinberg R.A. The hallmarks of cancer. Cell. - 2000 Jan7. - Vol. 100, №1. - P. 57-70.

11. Hanaban D., Weinberg R.A. Hallmarks of cancer: the next generation. Cell. - 2011 Mar 4. - Vol. 144, №5. - P. 646-74.

12. Harper K.L., Sosa M.S., Entenberg D., Hosseini H., Cheung J.F., Nobre R., Avivar-Valderas A., Nagi C., Girnius N., Davis R.J., Farias E.F., Condeelis J., Klein C.A., Aguirre-Ghiso J.A. Mechanism of early dissemination and metastasis in Her2(+) mammary cancer. Nature. - 2016. (in press).

13. Hosseini H., Obradović M.M., Hoffmann M., Harper K.L., Sosa M.S., Werner-Klein M., Nanduri L.K., Werno C., Ebrl C., Maneck M., Patwary N., Haunschild G., Gužvić M., Reimelt C., Grauvogl M., Eichner N., Weber F., Hartkopf A.D., Taran F.A., Brucker S.Y., Fehm T., Rack B., Buchbolz S., Spang R., Meister G., Aguirre-GhisoJ.A., Klein C.A. Early dissemination seeds metastasis in breast cancer. Nature. - 2016. (in press).

14. Husain H., Velculescu V.E. Cancer DNA in the Circulation: The Liquid Biopsy. JAMA. - 2017 Oct 3. - Vol. 318, №13. - P. 1272-1274.

15. Iyevleva A.G., Imyanitov E.N. Cytotoxic and targeted therapy for hereditary cancers. Hered Cancer Clin Pract. 2016 Aug 23. - Vol. 14, №1. - P. 17.

16. Linde N., Fluegen G., Aguirre-Ghiso J.A. The Relationship Between Dormant Cancer Cells and Their Microenvironment. Adv Cancer Res. - 2016. - Vol. 132. - P. 45-71.

17. Matsui A., Ibara T., Suda H., Mikami H., Semba K. Gene amplification: mechanisms and involvement in cancer. Biomol Concepts. - 2013 Dec. - Vol. 4, №6. - P. 567-82.

18. McGranahan N., Swanton C. Clonal Heterogeneity and Tumor Evolution: Past, Present, and the Future. Cell. 2017 Feb 9. - Vol. 168, №4. - P. 613-628.

19. Potter M., Newport E., Morten K.J. The Warburg effect: 80 years on. Biochem Soc Trans. - 2016 Oct 15. Vol. 44, №5. - P. 1499-1505.

20. Ramos E.K., Hoffmann A.D., Gerson S.L., Liu H. New Opportunities and Challenges to Defeat Cancer Stem Cells. Trends Cancer. - 2017 Nov. - Vol. 3, №11. - P. 780-796.

21. Rousseau P., Autexier C. Telomere biology: Rationale for diagnostics and therapeutics in cancer. RNA Biol. 2015. - Vol. 12, №10. - P. 1078-82.

22. Santamaria P.G., Moreno-Bueno G., Portillo F., Cano A. EMT: Present and future in clinical oncology. Mol Oncol. - 2017 Jul. - Vol. 11, №7. - P. 718-738.

23. Sokolenko A.P., Savonevich E.L., Ivantsov A.O., Raskin G.A., Kuligina E.S., Gorodnova T.V., Preobrazhenskaya E.V., Kleshchov M.A., Tiurin V.I., Mukhina M.S., Kotiv K.B., ShulgaA.V., Kuznetsov S.G., Berlev I.V., Imyanitov E.N. Rapid selection of BRCA1-proficient tumor cells during neoadjuvant therapy for ovarian cancer in BRCA1 mutation carriers. Cancer Lett. - 2017 Jul 1. - Vol. 397. - P. 127-132.

24. Staedtke V., Dzaye O.D.A., Holdhoff M. Actionable Molecular Biomarkers in Primary Brain Tumors. Trends Cancer. - 2016 Jul. - Vol. 2, №7. - P. 338-349.

25. Vogelstein B., Papadopoulos N., Velculescu V.E., Zbou S., Diaz L.A. Jr., Kinzler K.W. Cancer genome landscapes. Science. - 2013 Mar 29. - Vol. 339, №6127. - P. 1546-58.

\section{References}

1.Amirouchene-Angelozzi N., Swanton C., BardelliA. Tumor Evolution as a Therapeutic Target. Cancer Discov. 2017. (in press).

2. Antonarakis E.S., Lu C., Wang H., Luber B., Nakazawa M., Roeser J.C., Chen Y., Mobammad T.A., Chen Y., Fedor H.L., Lotan T.L., Zheng Q., De Marzo A.M., Isaacs J.T., Isaacs W.B., Nadal R., Paller C.J., Denmeade S.R., Carducci M.A., Eisenberger M.A., Luo J. AR-V7 and resistance to enzalutamide and abiraterone in prostate cancer. N Engl J Med. 2014 Sep 11; 371(11): 1028-38.

3. Bogdanova N., Helbig S., Dörk T. Hereditary breast cancer: ever more pieces to the polygenic puzzle. Hered Cancer ClinPract. 2013 Sep 11; 11(1): 12. doi: 10.1186/1897-4287-11-12.

4. Carmeliet P., Jain R.K. Molecular mechanisms and clinical applications of angiogenesis. Nature. 2011 May 19; 473(7347): 298-307.

5. Chatterjee A., Rodger E.J., Eccles M.R. Epigenetic drivers of tumour igenesis and cancer metastasis. Semin Cancer Biol. 2017. (in press).

6. Correa H. Li-Fraumeni Syndrome. J Pediatr Genet. 2016 Jun; 5(2): 84-8.

7. Croce C.M., Reed J.C. Finally, an Apoptosis-Targeting Therapeutic for Cancer. Cancer Res. 2016 Oct 15; 76(20): 5914-5920. doi: 10.1158/0008-5472.CAN-16-1248.

8. Dillon C.P., Green D.R. Molecular Cell Biology of Apoptosis and Necroptosis in Cancer. Adv Exp Med Biol. 2016; 930: 1-23. 
9. Granier C., De Guillebon E., Blanc C., Roussel H., Badoual C., Colin E., Saldmann A., Gey A., Oudard S., Tartour E. Mechanisms of action and rationale for the use of checkpoint inhibitors in cancer. ESMO Open. 2017 Jul 3; 2(2): e000213.

10. Hanaban D., Weinberg R.A. The hallmarks of cancer. Cell. 2000 Jan7; 100(1): 57-70.

11. Hanahan D., Weinberg R.A. Hallmarks of cancer: the next generation. Cell. 2011 Mar 4; 144(5): 646-74. doi: 10.1016/j.cell.2011.02.013.

12. Harper K.L., Sosa M.S., Entenberg D., Hosseini H., CheungJ.F., Nobre R., Avivar-Valderas A., Nagi C., Girnius N., Davis R.J., Farias E.F., Condeelis J., Klein C.A., Aguirre-Ghiso J.A. Mechanism of early dissemination and metastasis in Her2(+) mammary cancer. Nature. 2016. (in press).

13. Hosseini H., Obradović M.M., Hoffmann M., Harper K.L., Sosa M.S., Werner-Klein M., Nanduri L.K., Werno C., Ehrl C., Maneck M., Patwary N., Haunschild G., Gužvić M., Reimelt C., Grauvogl M., Eichner N., Weber F., Hartkopf A.D., Taran F.A., Brucker S.Y., Fehm T., Rack B., Buchbolz S., Spang R., Meister G., Aguirre-GhisoJ.A., Klein C.A. Early dissemination seeds metastasis in breast cancer. Nature. 2016. (in press).

14. Husain H., Velculescu V.E. Cancer DNA in the Circulation: The Liquid Biopsy. JAMA. 2017 Oct 3; 318(13): 12721274. doi: $10.1001 /$ jama.2017.12131.

15. Iyevleva A.G., Imyanitov E.N. Cytotoxic and targeted therapy for hereditary cancers. Hered Cancer Clin Pract. 2016 Aug 23; 14(1): 17.

16. Linde N., Fluegen G., Aguirre-Ghiso J.A. The Relationship Between Dormant Cancer Cells and Their Microenvironment. Adv Cancer Res. 2016; 132: 45-71.

17. Matsui A., Ihara T., Suda H., Mikami H., Semba K. Gene amplification: mechanisms and involvement in cancer. Biomol Concepts. 2013 Dec; 4(6): 567-82. doi: 10.1515/bmc-2013-0026.

18. McGranahan N., Swanton C. Clonal Heterogeneity and Tumor Evolution: Past, Present, and the Future. Cell. 2017 Feb 9; 168(4): 613-628.

19. Potter M., Newport E., Morten K.J. The Warburg effect: 80 years on. Biochem Soc Trans. 2016 Oct 15; 44(5): 1499-1505.

20. Ramos E.K., Hoffmann A.D., Gerson S.L., Liu H. New Opportunities and Challenges to Defeat Cancer Stem Cells. Trends Cancer. 2017 Nov; 3(11): 780-796.

21. Rousseau P., Autexier C. Telomere biology: Rationale for diagnostics and therapeutics in cancer. RNA Biol. 2015; 12(10): 1078-82.

22. Santamaria P.G., Moreno-Bueno G., Portillo F., Cano A. EMT: Present and future in clinical oncology. Mol Oncol. 2017 Jul; 11(7): 718-738. doi: 10.1002/1878-0261.12091. Epub 2017 Jun 27.

23. Sokolenko A.P., Savonevich E.L., Ivantsov A.O., Raskin G.A., Kuligina E.S., Gorodnova T.V., Preobrazhenskaya E.V., Kleshchov M.A., Tiurin V.I., Mukhina M.S., Kotiv K.B., Shulga A.V., Kuznetsov S.G., Berlev I.V., Imyanitov E.N. Rapid selection of BRCA1-proficient tumor cells during neoadjuvant therapy for ovarian cancer in BRCA1 mutation carriers. Cancer Lett. 2017 Jul 1; 397: 127-132.

24. Staedtke V., Dzaye O.D.A., HoldhoffM. Actionable Molecular Biomarkers in Primary Brain Tumors. Trends Cancer. $2016 \mathrm{Jul} ; 2(7): 338-349$.

25. Vogelstein B., Papadopoulos N., Velculescu V.E., Zhou S., Diaz L.A. Jr., Kinzler K.W. Cancer genome landscapes. Science. 2013 Mar 29; 339(6127): 1546-58. doi: 10.1126/science.1235122. 